\title{
3. Digital transformation, education, and adult learning in Malaysia
}

Rachel Gong, Ashraf Shaharudin, and Siti Aiysyah Tumin

Malaysia's government has long recognised the value and promise of technology and innovation, having begun in the I990s to develop a multimedia super corridor (MSC) to be competitive in a globally digitalised economy (Banerjee 1999). While digitalisation refers to the process of restructuring society around digital and communication infrastructures (Brennen and Kreiss 2016), digital transformation involves socio-technological changes that have broader and more profound implications on society and culture, such as the evolution of information dissemination from edited, curated print articles to unregulated, algorithmically recommended TikTok videos.

Despite its incomplete digital transformation, Malaysia emerged as a relatively well-connected country in Southeast Asia. As of 2019, Malaysia was a mobile-first nation, with a I $23 \%$ mobile broadband penetration rate and a $9 \%$ fixed broadband penetration rate. In populated areas, ${ }_{4} \mathrm{G}$ coverage was reportedly at $82 \%$ (MCMC 2020), albeit of questionable quality. Basic data plans are generally affordable, and the most popular online activities among internet users are social communications such as texting and social media (Gong 2020).

Efforts to further digitalise Malaysia had begun before the COVID-I9 pandemic. A national broadband infrastructure plan had been launched; programmes had been established to incorporate advanced digital technologies into economic sectors such as manufacturing; and various structural institutions, such as the civil service, institutes of higher learning, and legal courts, had begun incorporating digital services, cloud computing, and big data analysis into their workflows. However, the pandemic revealed in Malaysia, as elsewhere, the stark structural

How to cite this book chapter:

Gong, Rachel; Shaharudin, Ashraf; and Tumin, Siti Aiysyah. 2022. 'Digital transformation, education, and adult learning in Malaysia'. In: Shin, Hyun Bang;

Mckenzie, Murray; and Oh, Do Young (eds) COVID-I9 in Southeast Asia:

Insights for a post-pandemic world. London: LSE Press, pp. 46-57.

DOI: https://doi.org/IO.3I389/lsepress.cov.c License: CC BY 4.०. 
inequalities present in its digital infrastructure and adoption, a problem that had existed since the days of the MSC (Bunnell 2002). While digital technologies enabled elite segments of society to adapt fairly easily and quickly to life under lockdown, many under-served groups were not as fortunate.

In this chapter we assess the ways in which digital technologies, instead of levelling the playing field, may actually increase socio-economic inequalities, especially with regard to education and adult learning. We consider the segments of society who may be further marginalised in the future, given the changing conditions of learning and work accelerated by COVID-I9, and suggest how future research and policy can tackle these challenges.

Previously, the digital divide described a fundamental gap in terms of access to computers and the internet (DiMaggio et al. 200I). As computing power costs decreased and internet infrastructure became widespread, digital inequalities became not just about access but also about meaningful connectivity and use (A4AI 2020; Gong 2020; Hargittai, Piper, and Morris 20I8). The question is no longer simply whether everyone can connect to the internet, but also how we are connecting and how we are using our connectivity.

In the wake of the COVID-I9 pandemic, Malaysia recognised internet connectivity as a public utility (MOF 2020), paving the way for significant improvements in the development of internet infrastructure. While this may address the access component of the digital divide, it does not guarantee inclusive meaningful connectivity or use. During Malaysia's movement control orders to curb the spread of COVID-I9, schools and universities were closed. Despite their best efforts to pivot to online classes, teachers and students faced challenges in terms of both digital access and digital pedagogy. When offices closed, a divide emerged between workers who could work from home and workers who had to be physically present to do their (often essential) jobs. Income has been a good predictor of which side of this divide a worker might fall (Siti Aiysyah 2020).

Income has also been a good predictor of the likelihood of non-essential workers staying employed during the pandemic (Parker, Minkin, and Bennett 2020). The number of unemployed people in Malaysia rose $4 \mathrm{I} \%$ from $52 \mathrm{I}, 400$ in September 2019 to 737,500 in September 2020 (DOSM 2019; DOSM 2020c). Online education opportunities increased as part of adult learning initiatives to reskill and upskill job 
seekers. However, take-up of these programmes remained relatively low (Malay Mail 2020).

\section{Widening gaps in education}

We turn now to a discussion of the role and impact of digital technologies and the digital divide on education and adult learning. Malaysian school students lost at least I 7 out of 43 normal schooling weeks in 2020 due to school closures. Learning was disrupted for around 4.9 million pre-school, primary, and secondary school students (MOE 2020) and around I.3 million higher education students (MOHE 2020). Different and compounding forms of existing inequalities became apparent with distance learning.

The clearest gap was the lack of digital resources for some students, rendering digital learning almost impossible. Even before the pandemic made distance learning the default mode, students lacking the resources necessary to learn remotely were found to trail their peers in cognitive abilities and be more likely to drop out in the long run (Murat and Bonacini 2020). In 2019, only 6-9\% of Malaysian school students owned a personal computer and/or a tablet (Hawati and Jarud 2020). Unequal access to digital devices and the internet tended to follow the rural-urban and household income gaps (Figure 3.I), aggravating prevailing inequalities.

Approximately $77 \%$ of school students were unable to effectively learn digitally from home owing to limited digital access (Ashraf 2020). This likely lower-bound estimate was based on both fixed and mobile broadband access, though fixed broadband access has been much rarer and arguably more effective for learning. In 2019, Malaysia's average mobile download speed of I I.० Mbps was far slower than developed countries such as Canada (59.6 Mbps) and South Korea (59.0 Mbps) (Fenwick and Khatri 2020). States with lower median household incomes had lower fixed broadband subscription rates (Gong 2020), which implied a higher percentage of disadvantaged students in poorer states.

Distance learning requires self-discipline and self-initiative. A time use survey found that German students reduced their daily learning time by about half during school closures (Grewenig et al. 2020). The reduction was larger among low-achieving students as their learning time was replaced with less useful activities such as gaming or consuming social media, potentially further deteriorating their educational 
Figure 3.1. Internet subscription and personal computer and laptop ownership by household segment, 2019

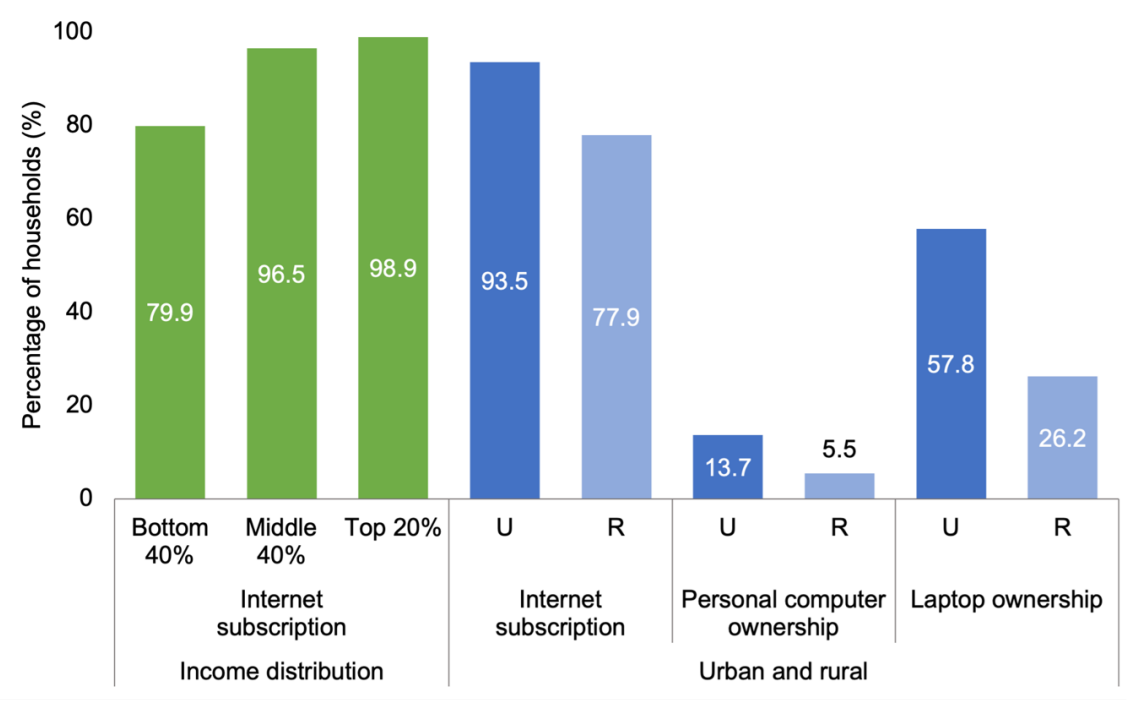

Source: DOSM (2020a).

achievement. This also highlights the discretionary nature of internet use, resulting in different outcomes for users. In 20I9, across Malaysia, while $86 \%$ of internet users engaged in social networking, only $60 \%$ and $56 \%$ used the internet to study and read online publications, respectively (Gong 2020).

Researchers discovered that, by April 2020, Google search intensity for online learning resources in the United States had doubled relative to pre-pandemic levels (Bacher-Hicks, Goodman, and Mulhern 202I). However, the demand for online resources was substantially lower in areas with lower income, lower internet access, and more rural schools. Malaysia likely experienced similar inequalities; based on crude observations, during the first lockdown, keyword searches for learning resources were higher in affluent states such as Selangor and Kuala Lumpur.

There was also a gender dimension to distance learning, which raises questions for further research and policy deliberation. In Malaysia, while the proportion of women in the population remained steady from $20 \mathrm{I} 2$ to $20 \mathrm{I} 8$, the proportion of internet users who were women declined (Gong 2020). Concurrently, the teaching profession was dominated by women, who disproportionately bore the burden of care work (KRI 20I9), which increased during lockdowns. 
Figure 3.2. Expenditure on education by decile income group, 2019
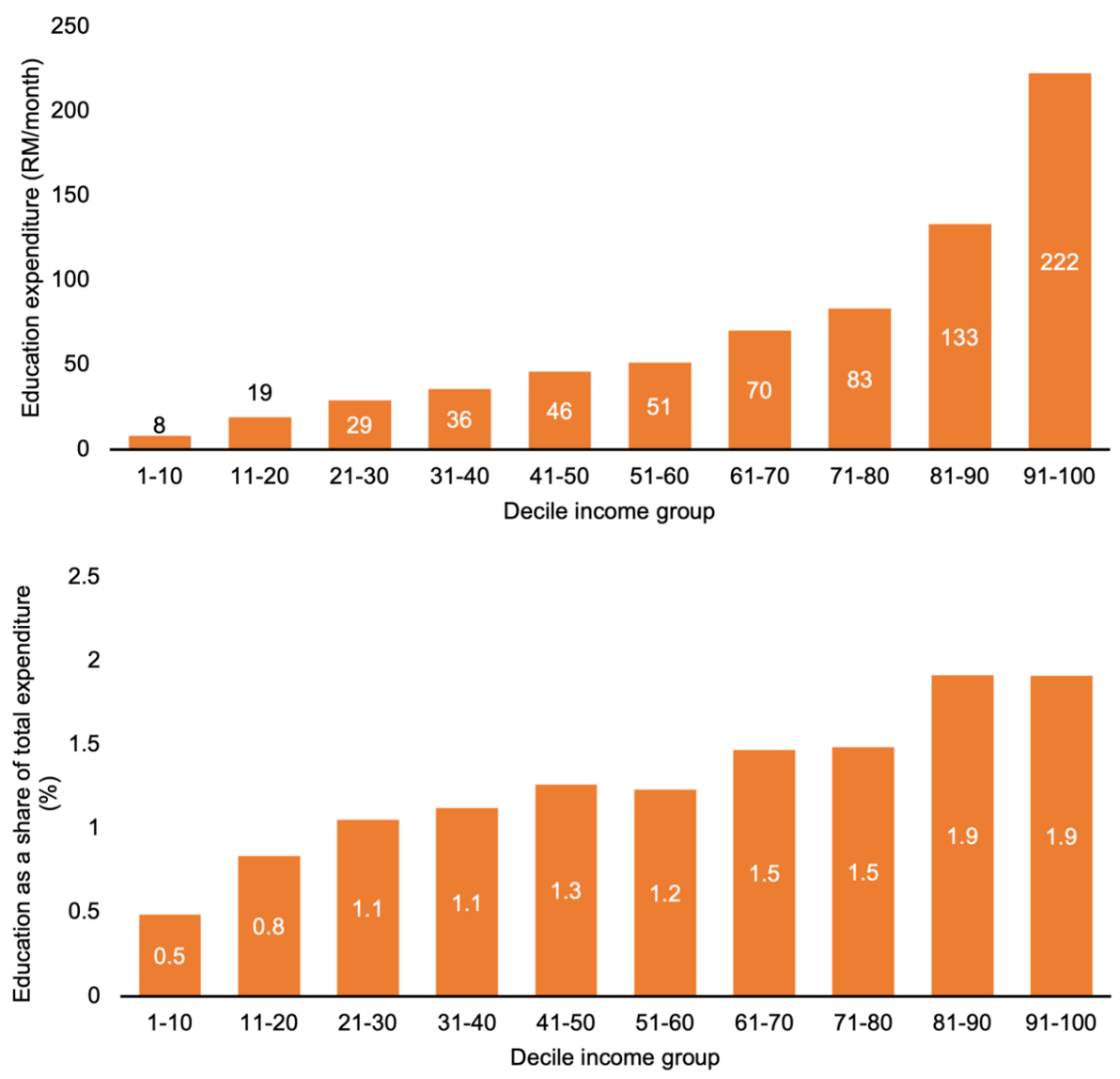

Source: DOSM (2020a).

Meanwhile, boys' disengagement from education was expected to worsen with distance learning (UNESCO 2020). The reduction in learning time due to school closure was larger for boys than for girls (Grewenig et al. 2020). This may have exacerbated the 'lost boys' problem in Malaysia, where boys made up only $30 \%$ of higher education enrolment. These 'lost boys' either left school early or did not further their education (KRI 20I8).

Without discrediting the benefits of education technology (edutech) for students and teachers alike, for-profit edutech has long-term consequences for how education as a public good is perceived and practised (Williamson, Eynon, and Potter 2020). In 20I9, poorer households in Malaysia spent considerably less on education than richer households did, both in absolute terms and as a proportion 
of their total expenditures (Figure 3.2) (DOSM 2020a). Further research is needed to understand how the increasing 'platformisation' of education impacts the education of poor and digitally disadvantaged households. While the pandemic hastened the adoption of digital technology in education, it is doubtful whether this was an inclusive digital transformation.

\section{Adult learning and digital exclusion}

The lack of digital inclusivity went beyond education. It also affected adult learning, which was essential given the changing nature of work due to technological advancements and globalisation (World Bank 20I9). COVID-I9 might have accelerated the effects of labour market megatrends such as automation and increased the incentive to substitute capital for labour (Bloom and Prettner 2020). This increased the importance of adult learning to ensure people remained competitive in the labour market.

Malaysian policymakers had been actively encouraging reskilling and upskilling prior to the pandemic. However, pre-pandemic participation in adult learning was generally underwhelming. The training participation rate among registered employers topped out at $25 \%$, compared to $49 \%$ in Singapore and $77 \%$ in Australia (HRDF 2019a). Only $33 \%$ of surveyed manufacturing firms offered formal training, far lower than peer countries (Nur Thuraya and Siti Aiysyah 2020). Lack of awareness, inadequate resources, overlapping programmes, and recognition issues have been cited as the main challenges of adult learning (HRDF 20I9c).

Participation in adult learning was unequal, with young and very old trainees under-represented. Adult learning at work was also skewed towards the skilled workforce, compared to the semi-skilled and low-skilled workforce (Figure 3.3). Unfortunately, COVID-I9 exacerbated the vulnerabilities of groups not actively participating in adult learning. Youth workers were found to be disproportionately adversely affected by the pandemic (Gonzalez, Gardiner, and Bausch 2020), while lower-skilled workers were most likely to be replaced if firms decided to automate their business operations during the pandemic (KRI 2020).

The digital divide further increased these inequalities. First, not all training programmes could be conducted online. In fact, the adoption rate of e-learning and mobile learning was less than $\mathrm{I} \%$ for Human 
Figure 3.3. HRDF trainees as a share of total employees, disaggregated by age and skill level, 2018

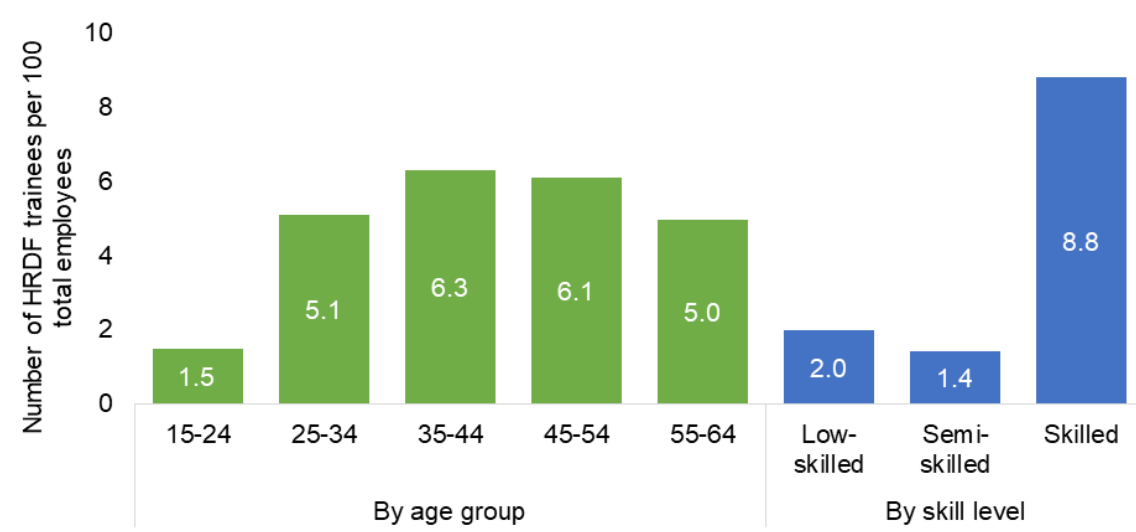

Sources: HRDF (2019c); HRDF (2020); DOSM (2020b).

Resource Development Fund (HRDF) training programmes in 2018 (HRDF 20I9b). Training for non-digital technical skills such as machine handling and safe food preparation could not be conducted online because they required practical learning activities.

Second, not all employers were supportive of employee training, as evident in the low training participation rates among employers. In economic downturns, employers face financial constraints in supporting workers' skills development. Additionally, the HRDF only covered selected sectors, and a substantial segment of the workforce not covered by the HRDF (micro-enterprises, workers in the informal sector, and the self-employed) could not afford to invest in adult learning.

Moreover, the lack of digital literacy among the older population has been a significant barrier in accessing online adult learning courses. More mature individuals were not only less likely to use the internet; they were also less likely to use it for learning purposes (Figure 3.4). Online adult learning was likely challenging for lower-income households too, as they faced higher trade-offs between spending on essential goods and investing in adult learning (Rao 2009). Poorer households also faced significant barriers to digital access that limited their adult learning opportunities (Siti Aiysyah 2020).

Reskilling and upskilling were important to help workers navigate the changing nature of work and employment challenges brought on by the pandemic. However, focusing solely on digital skills when many training providers, employers, and workers do not have the capacity 
Figure 3.4. Share of internet use by type of activity and age group, 2019 (percentage)
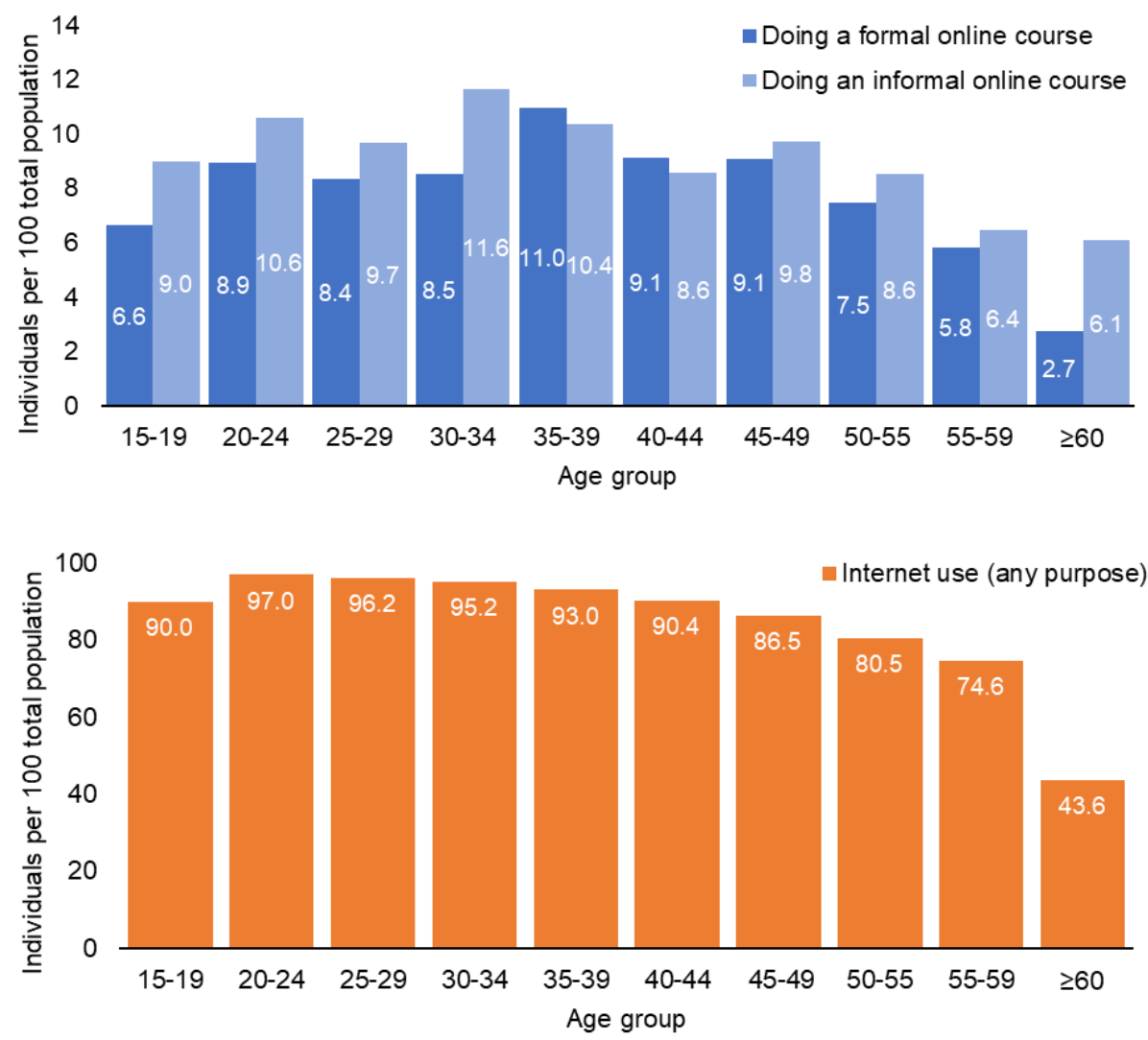

Source: DOSM (2020b).

to do so could further exacerbate existing structural issues in adult learning. Failure to address the digital gap among workers might also perpetuate inequality in the labour market.

\section{Conclusion}

The COVID-I9 pandemic accelerated digitalisation in many ways, but digital adoption has not been equitable. More research is needed to assess the long-term impacts of the digital divides described in this chapter. While distance schooling is unlikely to fully replace physical schooling for children, online learning is likely to be incorporated into teaching methods. Inclusive education requires an understanding of how digital and analogue inequalities affect educational attainment 
and subsequent socio-economic opportunities. Improving internet coverage and quality, increasing access to digital devices, and providing digital pedagogy training for teachers must be part of the national socio-economic agenda.

Businesses and governments were proactively encouraging online adult learning during the pandemic to enhance worker resilience. However, many adult learning programmes were costly and had limited participation and impact. These programmes did not consider different adult learning styles, competing family, care, and work demands, and socio-economic constraints (World Bank 20I9). Effective adult learning, offline or online, must address these challenges to bring returns to post-schooling human capital investment.

Broadly applying digital solutions to every available situation does not lead to an inclusive digital transformation. Rushed and improperly considered digital adoption is rife with unintended consequences. Diversity of input and research is needed, especially among groups typically under- or ill-served by digital technologies, in order to ensure that digital transformation is beneficial and sustainable for society in the long run.

\section{Acknowledgements}

All authors contributed equally to this work.

\section{References}

A4AI. (2020). Meaningful Connectivity: Raising the Bar for Internet Access. USA: World Wide Web Foundation. https://perma.cc/4MQ9-PK87 [Last accessed 22 April 202I].

Ashraf, Shaharudin. (2020). Reopening Schools: Giving Access to Education Equitably and Safely. Malaysia: Khazanah Research Institute. https://perma .cc/VUE4-93X8 [Last accessed 22 April 202I].

Bacher-Hicks, Andrew; Goodman, Joshua; and Mulhern, Christine. (202I). 'Inequality in household adaptation to schooling shocks: Covid-induced online learning engagement in real time'. Journal of Public Economics, vol. I93, p. I04345. https://doi.org/IO.IOI6/j.jpubeco.2020.I04345

Banerjee, Indrajit. (I999). 'Malaysia's multimedia super corridor: One-stop super shop or highway to progress and prosperity for all?' Convergence, vol. 5, no. 3, pp. IO6-I I 5. https://doi.org/IO.I I 77\% 2FI 35485659900 500308 
Bloom, David; and Prettner, Klaus. (2020). 'The macroeconomic effects of automation and the role of COVID-I9 in reinforcing their dynamics'. VoxEU, 25 June. https://perma.cc/PXD8-P 557 [Last accessed 22 April 202 I].

Brennen, J. Scott; and Kreiss, Daniel. (2016). 'Digitalization', in K.B. Jensen and R.T. Craig (eds) The International Encyclopedia of Communication Theory and Philosophy. UK: Wiley-Blackwell, pp. 556-566.

Bunnell, Tim. (2002). 'Multimedia utopia? A geographical critique of high-tech development in Malaysia's multimedia super corridor'. Antipode, vol. 34, no. 2, pp. 265-295. https://doi.org/IO. I I I I/I 467-8330.00238

DiMaggio, Paul; Hargittai, Eszter; Celeste, Coral; and Shafer, Steven. (200I). From Unequal Access to Differentiated Use: A Literature Review and Agenda for Research on Digital Inequality. USA: Russell Sage Foundation. https://perma.cc/G7U8-4477 [Last accessed 22 April 202I].

DOSM (Department of Statistics Malaysia). (2019). Key Statistics of Labour Force in Malaysia September 2019. Malaysia: Department of Statistics Malaysia. https://perma.cc/43UL-NY22 [Last accessed I I January 202I].

DOSM. (2020a). Households Expenditure Survey Report 2019. Malaysia: Department of Statistics Malaysia. https://perma.cc/LTT4-FAHA [Last accessed I I January 202I].

DOSM. (2020b). ICT Use and Access by Individuals and Households Survey Report 2019. Malaysia: Department of Statistics Malaysia. https://perma.cc /AK8U-N7LQ [Last accessed I I January 202I].

DOSM. (2020c). Key Statistics of Labour Force in Malaysia September 2020. Malaysia: Department of Statistics Malaysia. https://perma.cc/8A6L-SXXK [Last accessed I I January 202I].

Fenwick, Sam; and Khatri, Hardik. (2020). The State of Mobile Network Experience 2020: One Year Into the 5 G Era. UK: Opensignal. https://perma .cc/2U7D-JPPT [Last accessed 22 April 202I].

Gong, Rachel. (2020). Digital Inclusion: Assessing Meaningful Internet Connectivity in Malaysia. Malaysia: Khazanah Research Institute. https:// perma.cc/4NUB-4JLG [Last accessed 22 April 202I].

Gonzalez, Susana Puerto; Gardiner, Drew; and Bausch, Jo. (2020). Youth and COVID-I 9: Impacts on Jobs, Education, Rights and Mental Well-Being: Survey Report 2020. Switzerland: International Labour Organization. https://perma.cc/SAL9-HYB4 [Last accessed 22 April 202I].

Grewenig, Elisabeth; Lergetporer, Philipp; Werner, Katharina; Woessmann, Ludger; and Zierow, Larissa. (2020). COVID-I9 and Educational Inequality: How School Closures Affect Low-and High-Achieving Students. 
Germany: IZA Institute of Labor Economics. https://perma.cc/595R-Z874 [Last accessed 22 April 202I].

Hargittai, Eszter; Piper, Anne Marie; and Morris, Meredith Ringel. (2018). 'From internet access to internet skills: Digital inequality among older adults'. Universal Access in the Information Society, vol. I 8, pp. 88I-890. https://doi.org/IO.I007/sI0209-0I8-06I7-5

Hawati, Abdul Hamid; and Jarud, Romadan Khalidi. (2020). Covid-I9 and Unequal Learning. Malaysia: Khazanah Research Institute. https://perma .cc/5 YHQ-7NSC [Last accessed 22 April 202I].

HRDF (Human Resource Development Fund). (20I9a). HRDF Industry Training Participation Report 2019. Malaysia: Human Resource Development Fund. https://perma.cc/WB29-TFXW [Last accessed 22 April 202I].

HRDF. (20I9b). Human Capital Report Issue 06: Adoption of E-learning. Malaysia: Human Resource Development Fund. https://perma.cc/K9AL -CX6U [Last accessed 22 April 202I].

HRDF. (2019c). Human Capital Report Issue 09: Adult Lifelong Learning. Malaysia: Human Resource Development Fund. https://perma.cc/AMP7 -NKG3 [Last accessed 22 April 202I].

HRDF. (2020). Industry Training Intelligence Report Issue 03: Training Inequality According to Job Levels. Malaysia: Human Resource Development Fund. https://perma.cc/NPN6-LP2T [Last accessed 22 April 202I].

KRI (Khazanah Research Institute). (2018). The School-to-Work Transition of Young Malaysians. Malaysia: Khazanah Research Institute. https://perma.cc /C69W-XB84 [Last accessed 22 April 202I].

KRI. (20I9). Time to Care: Gender Inequality, Unpaid Care Work and Time Use Survey. Malaysia: Khazanah Research Institute. https://perma.cc/ $\mathrm{H}_{45} 6$ $-\mathrm{Z}_{3} \mathrm{XW}$ [Last accessed 22 April 202I].

KRI. (2020). Work in an Evolving Malaysia. Malaysia: Khazanah Research Institute. https://perma.cc/GBE2-7KBY [Last accessed 22 April 202I].

Malay Mail. (2020). 'I6,000 participants signed up for MDEC's free online courses, says CEO', 26 June. https://perma.cc/U7JK-UJR9 [Last accessed 22 April 202I].

MCMC (Malaysian Communications and Multimedia Commission). (2020). Industry Performance Report 2019. Malaysia: Malaysian Communications and Multimedia Commission. https://perma.cc/64SC-F 55 X [Last accessed 22 April 202I].

MOE (Ministry of Education). (2020). Statistik Bilangan Sekolah, Murid and Guru [MS]. Malaysia: Ministry of Education Malaysia. https://perma.cc /L 5 NT-P2SM [Last accessed 6 January 202I]. 
MOF (Ministry of Finance). (2020). Budget 202 I Speech. Malaysia: Ministry of Finance. https://perma.cc/58NG-KRT4 [Last accessed 22 April 202I].

MOHE (Ministry of Higher Education). (2020). Statistik Pendidikan Tinggi 2019 [MS]. Malaysia: Ministry of Higher Education Malaysia. https:// www.mohe.gov.my/en/download/awam/statistik/20I9-I [Last accessed 22 April 202I].

Murat, Marina; and Bonacini, Luca. (2020). Coronavirus Pandemic, Remote Learning and Education Inequalities. Global Labor Organization (GLO). https://perma.cc/RF4R-WRU9 [Last accessed 22 April 202I].

Nur Thuraya, Sazali; and Siti Aiysyah, Tumin. (2020). Leaving No Worker Behind: Deficit in Decent Work. Malaysia: Khazanah Research Institute. https://perma.cc/E $3 \mathrm{D}_{3}-\mathrm{K}_{4} \mathrm{NH}$ [Last accessed 22 April 202I].

Parker, Kim; Minkin, Rachel; and Bennett, Jesse. (2020). Economic Fallout from COVID-I9 Continues to Hit Lower-Income Americans the Hardest. USA: Pew Research Center. https://perma.cc/CAV4-MYRH [Last accessed 22 April 202I].

Rao, Ramesh. (2009). 'Digital divide: Issues facing adult learners'. Computer and Information Science, vol. 2, no. I, pp. I32-I 36. https://doi.org/I0.5539 /cis.v2nIpI 32

Siti Aiysyah, Tumin. (2020). Covid-I9 and Work in Malaysia: How Common Is Working from Home? LSE Southeast Asia Blog, 23 November. https:// perma.cc/H $\mathrm{H}_{3} \mathrm{PY}-\mathrm{UK}_{4} \mathrm{G}$ [Last accessed $22 \mathrm{Apr} 2 \mathrm{O} 2 \mathrm{I}$ ].

UNESCO. (2020). Addressing the Gender Dimensions of COVID-Related School Closures. France: UNESCO. https://perma.cc/8VYK-PJWL? [Last accessed 22 April 202I].

Williamson, Ben; Eynon, Rebecca; and Potter, John. (2020). 'Pandemic politics, pedagogies and practices: Digital technologies and distance education during the coronavirus emergency'. Learning, Media and Technology, vol. 45, no. 2, pp. I07-I I 4. https://doi.org/IO.IO80/I 7439884.2020.I76 I 64 I

World Bank. (2019). World Development Report 20 I9: The Changing Nature of Work. USA: World Bank. https://perma.cc/9C2X-5ZV6 [Last accessed 22 April 202I]. 